\title{
Wettability alteration analysis of smart water/novel functionalized nanocomposites for enhanced oil recovery
}

\author{
Sara Habibi ${ }^{1} \cdot$ Arezou Jafari $^{1} \cdot$ Zahra Fakhroueian $^{2}$
}

Received: 25 May 2019 / Published online: 16 April 2020

(c) The Author(s) 2020

\begin{abstract}
Smart water flooding, as a popular method to change the wettability of carbonate rocks, is one of the interesting and challenging issues in reservoir engineering. In addition, the recent studies show that nanoparticles have a great potential for application in EOR processes. However, little research has been conducted on the use of smart water with nanoparticles in enhanced oil recovery. In this study, stability, contact angle and IFT measurements and multi-step core flooding tests were designed to investigate the effect of the ionic composition of smart water containing $\mathrm{SO}_{4}{ }^{2-}$ and $\mathrm{Ca}^{2+}$ ions in the presence of nanofluid on EOR processes. The amine/organosiloxane@ $\mathrm{Al}_{2} \mathrm{O}_{3} / \mathrm{SiO}_{2}$ (AOAS) nanocomposite previously synthesized using co-precipitation-hydrothermal method has been used here. However, for the first time the application of this nanocomposite along with smart water has been studied in this research. Results show that by increasing the concentrations of calcium and sulfate ions in smart water, oil recovery is improved by $9 \%$ and $10 \%$, respectively, compared to seawater. In addition, the use of smart water and nanofluids simultaneously is very effective on increasing oil recovery. Finally, the best performance was observed in smart water containing two times of sulfate ions concentration (SW2S) with nanofluids, showing increased efficiency of about $7.5 \%$.
\end{abstract}

Keywords Smart water $\cdot$ Nanofluid $\cdot$ Wettability alteration $\cdot$ Contact angle $\cdot$ Stability $\cdot$ Enhanced oil recovery

\section{Introduction}

On average, two-thirds of the oil remains in oil reservoirs after the primary and secondary production (injection of water). Despite the constant supply of crude oil, the demand for it is increasing due to the industrial development and the global population growth. These factors have led to an

Edited by Yan-Hua Sun

Electronic supplementary material The online version of this article (https://doi.org/10.1007/s12182-020-00436-y) contains supplementary material, which is available to authorized users.

Arezou Jafari

ajafari@modares.ac.ir

$\triangle$ Zahra Fakhroueian

fakhroueian@ut.ac.ir

1 Chemical Engineering Faculty, Tarbiat Modares University, Tehran, Iran

2 School of Chemical Engineering, College of Engineering, Institute of Petroleum Engineering, University of Tehran, Tehran, Iran increase in oil prices and the need to define and implement enhanced oil recovery projects (Kokal and Al-Kaabi 2010; Stosur et al. 2003). There are different EOR methods such as chemical, thermal and microbial processes. Chemical flooding such as polymer flooding, injection of alkaline or similar compounds is limited due to the high cost of injectable materials, their corrosion potential and the loss of injectable materials during movement in the reservoir (Elyaderani and Jafari 2019; Engeset 2012; Yousefvand and Jafari 2018).

Due to their small size $(1-100 \mathrm{~nm})$, nanoparticles can enter into the pores without sticking to them. This will reduce the amount of injectable matter during flood processes. Nanoparticles are more environmentally friendly compared to other materials used in chemical flooding techniques. However, a large amount of energy is required to transform and eliminate them, which makes it easier to use nanoparticles in deep and high-pressure reservoirs. Nanofluids increase the efficiency of oil reservoirs through various mechanisms such as reduction of contact angle, which changes the wettability from oil wet to water wet. The ability of water flooding in EOR processes is improved by changing the wettability properties of the 
rock (Elyaderani et al. 2019; Engeset 2012; Gharibshahi et al. 2015; Kong and Ohadi 2010; Qiu 2010).

In an experimental attempt by Nazari Moghaddam et al. (2015), the impact of various nanofluids [zirconium dioxide $\left(\mathrm{ZrO}_{2}\right)$, calcium carbonate $\left(\mathrm{CaCO}_{3}\right)$, titanium dioxide $\left(\mathrm{TiO}_{2}\right)$, silicon dioxide $\left(\mathrm{SiO}_{2}\right)$, magnesium oxide $(\mathrm{MgO})$, aluminum oxide $\left(\mathrm{Al}_{2} \mathrm{O}_{3}\right)$, cerium oxide $\left(\mathrm{CeO}_{2}\right)$ and carbon nanotube (CNT)] on the wettability of carbonate rocks was studied (Nazari Moghaddam et al. 2015). Nwidee et al. (2016) studied the potential of zirconium oxide nanoparticles in limestone formations for EOR (Nwidee et al. 2016). Many researchers have attempted to investigate the ability of nanoparticles to change the wettability of porous media (Al-Anssari et al. 2016; Karimi et al. 2012; Nazari Moghaddam et al. 2015; Roustaei and Bagherzadeh 2015).

According to the reports, injection of different nanoparticles into the porous medium causes changes in wettability and sometimes interfacial tension (IFT). However, in some cases, there is no change in IFT (Fan and Striolo 2012). In general, the ability of nanofluids to be adsorbed at the contact surface between nanoparticles and rocks and the oil-water interface changes the wettability and interfacial tension (Binks and Whitby 2004). In fact, the amount of adsorption determines the ability of these two parameters. Therefore, to adsorb nanoparticles on these interfaces, their surface activity can be improved by modifying the surface of the nanoparticles. For instance, it has been shown that the ether groups in the chain of silanic compounds are used to cause surface water wetting, as reported by Yan et al. (2015) (Yan et al. 2015). Behzadi and Mohammadi (2016) investigated the surface modification of nanosilica by measuring the contact angle and IFT for EOR process (Behzadi and Mohammadi 2016). Therefore, there have been extensive studies of investigation of surface modification of nanoparticles in different fields (Lan et al. 2007; Lei et al. 2016; Li et al. 2013; Metin et al. 2012; Sun et al. 2005).

On the other hand, recent studies indicate that water flooding can be improved by considerable lowering of the salinity and ionic exchange of injection brine. Yousef et al. (2011) reviewed the effect of salinity changes on oil recovery factor in carbonate rocks. They found that the change in seawater salinity would have a significant potential for increasing oil production. In addition, by diluting the seawater, the wettability of the rock will go further toward water wetness (Yousef et al. 2011). By performing a series of experimental works, Awolayo et al. (2016) examined the effect of sulfate ion in smart water in carbonate reservoir on enhanced oil recovery. They found that by increasing the concentration of sulfate ion in injectable brine, the oil recovery factor increases significantly (Awolayo et al. 2016). Many works were subsequently performed, demonstrating that smart water can play a remarkable role in EOR processes (Pierre et al. 1990; Puntervold et al. 2015; Rashid et al. 2015; Zhang and Austad 2006; Zhang et al. 2006).

So far, there has been some discussion on water chemistry of dispersion fluid of nanoparticle. Hendraningrat and Torsæter (2016) examined the effect of salinity and ionic composition of injected brine on the performance of nanoparticles in enhanced oil recovery by measuring the contact angle and core flooding for sandstone rock. They found that the presence of divalent ions in nanofluid solutions, compared to monovalent ions, could increase the oil recovery factor of sandstone rocks (Hendraningrat and Torsæter 2016). Similar results have been reported by other researchers in this field (Kiani et al. 2016; Sulaiman et al. 2015).

The objective of this research was to apply the synthetic functionalized alumina/silica nanocomposite by siloxane and amine agent in EOR processes. In addition, to investigate the effect of water chemistry like ionic exchange $\left(\mathrm{Ca}^{2+}\right.$ and $\mathrm{SO}_{4}{ }^{2-}$ ) of brine on oil recovery factor, the combined method of nanofluid and smart water was utilized. In this study, different concentrations of sulfate and calcium were used ( 0 and 2 times). Therefore, the wettability alteration was examined in carbonate rock sections by contact angle measurement. Finally, oil recovery factor was investigated by flooding into carbonate core plug.

\section{Experimental section}

\subsection{Materials}

All the materials used in the synthesis of brines and functionalized nanocomposites were purchased from Merck and Aldrich Chemical Companies. Table 1 illustrates the properties of crude oil. In addition, the carbonate rock was obtained from a reservoir, southwest Iran (Gachsaran). Four core samples were used for flooding experiments. The properties of core plugs are shown in Table 2.

\subsection{Synthesis and characterization of amine/ organosiloxane@ $\mathrm{Al}_{2} \mathrm{O}_{3} / \mathrm{SiO}_{2}$ (AOAS) nanocomposite}

Silica mineral is the most abundant material on the planet's surface and can be produced and used at a low cost. Also, the surface of this material is modifiable and can be applied for various purposes by making it functional. In this research, silica and alumina nanoparticles have been applied which are widely applied in EOR processes and completely matched

Table 1 Crude oil properties

\begin{tabular}{llll}
\hline Asphaltene content, \% & Density, g/cm & Viscosity, cP & API gravity \\
\hline 2.9 & 0.899 & 14.52 & 25 \\
\hline
\end{tabular}


Table 2 Properties of core plugs

\begin{tabular}{|c|c|c|c|c|c|c|}
\hline Plug No. & Length, $\mathrm{cm}$ & Diameter, cm & Pore volume, $\mathrm{mL}$ & Porosity, \% & Permeability, mD & $\begin{array}{l}\text { Initial water } \\
\text { saturation, \% }\end{array}$ \\
\hline 1 & 8.6 & 3.8 & 8.36 & 8.57 & 0.57 & 35.8 \\
\hline 2 & 7.2 & 3.8 & 8.36 & 10.24 & 0.59 & 33.4 \\
\hline 3 & 8.7 & 3.8 & 9.31 & 9.44 & 0.53 & 31.2 \\
\hline 4 & 6.3 & 3.8 & 8.2 & 11.5 & 0.54 & 30.3 \\
\hline
\end{tabular}

with this environment. This functionalized nanocomposite was synthesized in the previous Authors' work. In this research, the process was briefly explained as follows: (1) Preparation of alumina/silica nanocomposite: $20 \mathrm{~g} \mathrm{AlCl}_{3}$ was mixed with the solution of tetraethyl orthosilicate $(30 \mathrm{~g})$, ethanol and distilled water and then heated. Moreover, a cooled alkaline solution of potassium hydroxide was gently poured into the previous solution. Afterward, the final mixture was cold refluxed for half an hour and was refluxed for $3 \mathrm{~h}$ at $70{ }^{\circ} \mathrm{C}$. Finally, the mixture was washed and dried. (2) A solution of hexane, dimethylformamide and toluene was added to the mixture of polydimethylsiloxane (PDMS) and alumina/silica. Then, the resulting solution was refluxed and heated. Moreover, $2 \mathrm{~g}$ of hexamethylenetetramine in distilled water was poured into the solution of $20 \mathrm{~mL}$ octylamine and ethanol. Finally, the product was synthesized after refluxing, washing and heating. Fourier transform infrared (FTIP) spectroscopy analyses, dynamic light scattering (DLS) and zeta potential measurements were carried out. In this research, a Malvern zeta-sizer nano instrument was applied for nanoparticles in the aqueous phase.

\subsection{Preparation of solutions}

Some synthetic seawater was designed to evaluate the impact of calcium and sulfate ions in different concentrations (0 and 2 times). In order to compare the effect of ions on oil recovery factor, brines were considered to have the same ionic strength as that of the seawater (Persian Gulf). Sodium chloride $(\mathrm{NaCl})$ was also used to adjust the ionic strength. Table 3 shows the molar compositions of various brines used in contact angle and core flooding tests (SWXCa where $\mathrm{X}$ shows $\mathrm{X}$ times the $\mathrm{Ca}^{2+}$ concentration of seawater). According to the observations in Sect. 3.2, the nanofluid is stable only in the concentration of $50 \mathrm{ppm}$ in specified synthetic seawater. As a result, $50 \mathrm{ppm}$ of nanofluid is added to the brines. Therefore, in this research, smart water and smart water with nanofluid were prepared as the main test solutions.

\subsection{Stability analysis}

In this research, two quantitative and qualitative methods have been used to study the stability of nanofluid with smart water solutions. In the qualitative studies, after preparing the desired solution, it was placed in a transparent and closed small container for a few hours to several days away from light and heat and photographs were taken at various time intervals. If no significant deposition and color variation were observed, the solution was considered stable in qualitative terms. An OPTIZEN 3220UV UV-visible spectrophotometer and a Malvern zeta-sizer nano instrument were used to ensure the stability of the nanofluids and quantitative investigations. In fact, the amount of light absorption passing through the solutions was measured at different times by the UV-visible spectrophotometer. In other words, the absorbance of light by distilled water at all wavelengths is zero. Therefore, the amount of light absorption decreases with deposition, approaching that of distilled water. All measurements were conducted at the maximum absorbance indicated by the apparatus for each solution $(200 \mathrm{~nm})$. In

Table 3 Molar composition of synthetic seawater

\begin{tabular}{|c|c|c|c|c|c|c|c|}
\hline \multirow[t]{2}{*}{ Brine } & \multicolumn{5}{|c|}{ Concentration, mol/L } & \multirow{2}{*}{$\begin{array}{l}\text { Total dissolved solid, } \\
\mathrm{g} / \mathrm{L}\end{array}$} & \multirow{2}{*}{$\begin{array}{l}\text { Ionic } \\
\text { strength, } \\
\mathrm{mol} / \mathrm{L}\end{array}$} \\
\hline & $\mathrm{Na}^{+}$ & $\mathrm{Mg}^{2+}$ & $\mathrm{Ca}^{2+}$ & $\mathrm{Cl}^{-}$ & $\mathrm{SO}_{4}{ }^{2-}$ & & \\
\hline Seawater & 0.460 & 0.045 & 0.013 & 0.530 & 0.024 & 33.20 & 0.659 \\
\hline SW0Ca & 0.499 & 0.045 & 0 & 0.543 & 0.024 & 34.04 & 0.659 \\
\hline $\mathrm{SW} 2 \mathrm{Ca}$ & 0.421 & 0.045 & 0.026 & 0.517 & 0.024 & 32.37 & 0.659 \\
\hline SWOS & 0.484 & 0.045 & 0.013 & 0.602 & 0 & 34.01 & 0.659 \\
\hline SW2S & 0.436 & 0.045 & 0.013 & 0.458 & 0.048 & 32.40 & 0.659 \\
\hline Formation water & 3.649 & 4.041 & 0.010 & 0.194 & 0.012 & 236.226 & 10.049 \\
\hline
\end{tabular}


addition, the nanoparticle size distribution over time was measured by the DLS method to examine the tendency of nanoparticles to sediment.

\subsection{Contact angle and IFT measurements}

Interfacial tension of oil/water was measured by the pendant drop method in the presence of AOAS nanocomposites and smart water. The average value of three different measurements for each sample was used to obtain reliable results from these measurements. Contact angle measurement was used to determine the rock wettability in brine (smart water) and brine with nanofluid solutions. At first, polished carbonate slices were cut in a coin shape with a thickness of $2 \mathrm{~mm}$. The plates were subjected to Soxhlet extraction with methanol for $24 \mathrm{~h}$ to remove any salt, followed by washing with toluene for 7 days, washing with distilled water and drying in an oven at $75{ }^{\circ} \mathrm{C}$ for a day. The plates were then aged in crude oil for 2 weeks and placed vertically in the prepared solutions for $24 \mathrm{~h}$ in the end (Karimi et al. 2012; Rashid et al. 2015; Roustaei et al. 2012). For measuring the contact angle, a drop of oil was gently injected into the cell containing the aqueous phase. The oil droplet was then photographed by a camera attached to the rock surface, and the picture was analyzed with the accuracy of $\mp 1^{\circ}$ using the system software. The schematic of this apparatus is shown in Fig. 1.

\subsection{Core flooding experiments}

The coreflood apparatus includes two high-pressure cylinders to transport the fluid, such as formation water, oil and nanofluid with smart water. Figure 2 shows the different parts of this system. Each core plug was cleaned the same way as plates which indicated in Sect. 2.5. After placing the sample in the core holder and subjecting it to vacuum, the main valve inlet was opened and connected to the cylinders containing the formation water until the sample was completely saturated. The permeability was measured by injecting brine at different rates and measuring the pressure drop between the two ends of the core sample. The weight of the wet core sample was then determined to measure its porosity. In the next step, 5 pore volumes of the oil were injected into the saturated core. By measuring the initial volume of the water in the core and reducing the amount of outlet water by the injection of oil, the initial water saturation was calculated $\left(S_{\mathrm{wi}}\right)$. The cores were placed in oil for 4 weeks at $75^{\circ} \mathrm{C}$ and atmospheric pressure in order to carry out the aging process and draw the core to the wettability conditions in the reservoir. Afterward, seawater was injected, followed by the secondary water flooding, until no oil was removed from the core. Smart water and smart water with nanofluid were subsequently injected. Hence, in each experiment, three stages of flooding tests were performed. Furthermore, the ions were evaluated by calculating the ratio of the output concentration to the input of active ions in solutions using ion chromatography.

\section{Results and discussion}

\subsection{Characterization of amine/organosiloxane@ $\mathrm{Al}_{2} \mathrm{O}_{3} / \mathrm{SiO}_{2}$ (AOAS) nanocomposite}

The Fourier transform infrared (FTIR) spectrum of functionalized $\mathrm{Al}_{2} \mathrm{O}_{3} / \mathrm{SiO}_{2}$ nanocomposite is shown in Fig. 3. It demonstrates the functional groups of synthesized nanoparticles. Results illustrate that the absorption peak at $3400 \mathrm{~cm}^{-1}$ is

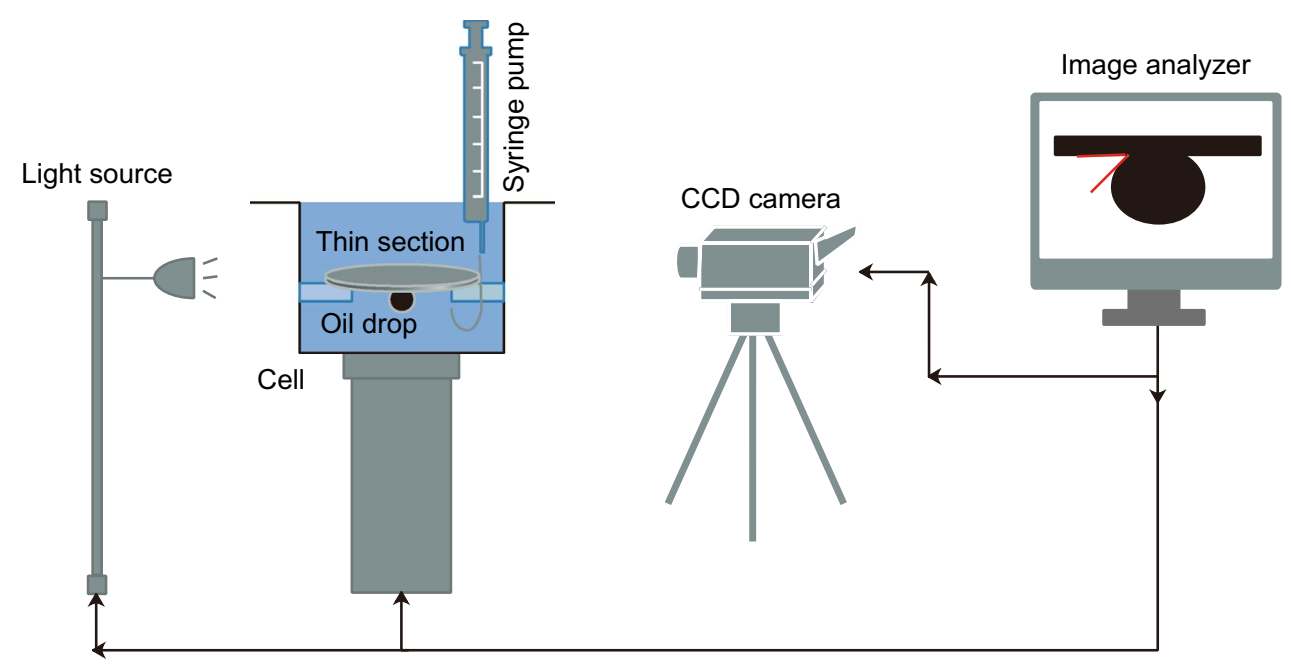

Fig. 1 Schematic of contact angle measurement apparatus 


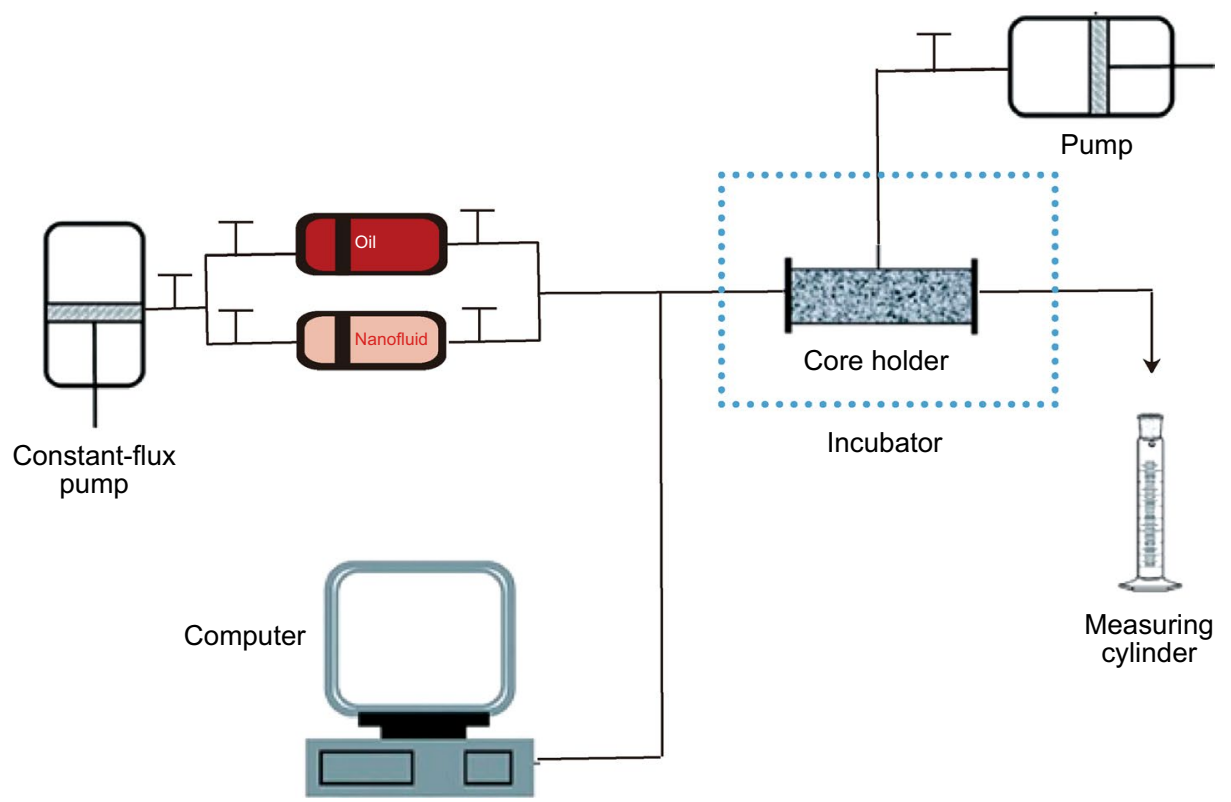

Fig. 2 Schematic of core flooding apparatus

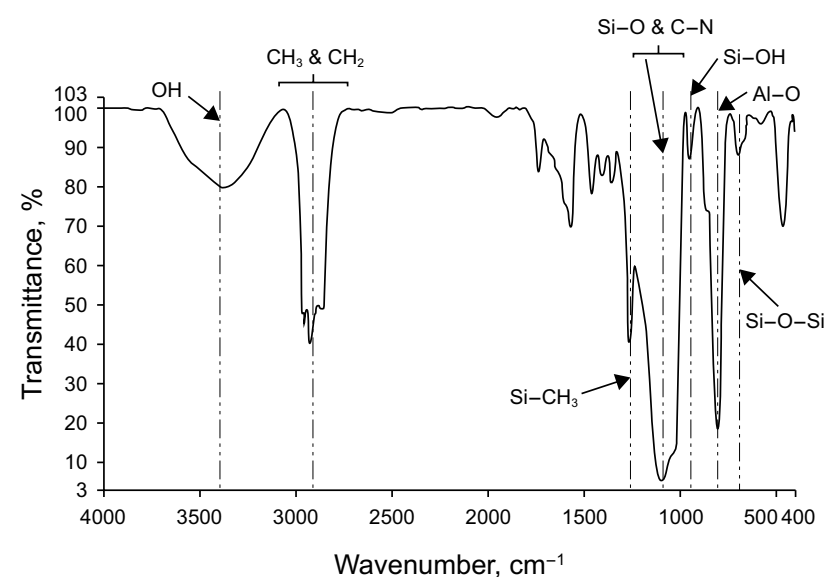

Fig. 3 FTIR spectrum of amine/organosiloxane @ $\mathrm{Al}_{2} \mathrm{O}_{3} / \mathrm{SiO}_{2}$ (AOAS) nanocomposite

attributed to the tensile vibration of - $\mathrm{OH}$ related to the water molecules on the nanoparticle surface (Metin et al. 2011). Also, the peak at $1100 \mathrm{~cm}^{-1}$ is observed in the FTIR spectrum of silica structure ( $\mathrm{Si}-\mathrm{O})$. As observed in Fig. 3, the peak associated with the Al-O bond occurs in the range of 400-900 $\mathrm{cm}^{-1}$ (Damayanti 2010; Gao et al. 2017; Tokoro et al. 2014). In addition, the $\mathrm{N}-\mathrm{C}$ bonds appear in the range of $1080-1360 \mathrm{~cm}^{-1}$ which is related to the hexamethylenetetramine. The peak at 1260 and $800 \mathrm{~cm}^{-1}$ corresponding to the $\mathrm{Si}-\mathrm{CH}_{3}$ and $\mathrm{Si}-\mathrm{OH}$ bonds are presented in the FTIR spectrum of PDMS (Johnson et al. 2013). The size of particles and particle distribution of functionalized nanocomposite is illustrated by DLS measurements. Figure 4

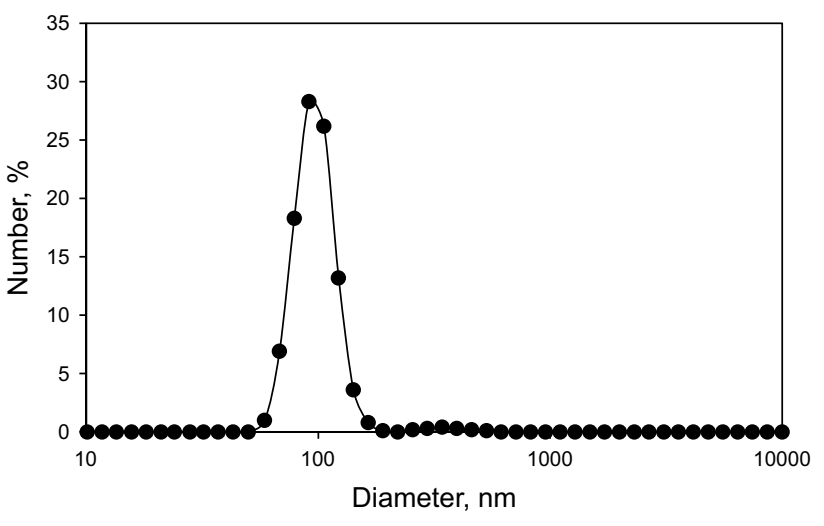

Fig. 4 Dynamic light scattering results for amine/organosiloxane@ $\mathrm{Al}_{2} \mathrm{O}_{3} / \mathrm{SiO}_{2}$ (AOAS) nanocomposite

demonstrates that the dominant size of amine/organosiloxane@ $\mathrm{Al}_{2} \mathrm{O}_{3} / \mathrm{SiO}_{2}$ is $91.28 \mathrm{~nm}$. Furthermore, the zeta potential of this nanocomposite is $-26 \mathrm{mV}$. This indicates that the net surface charge of AOAS nanocomposite is negative which means the nanoparticle has superficial groups with negative charges.

\subsection{Stability and nanofluid concentration determination}

In this section, the qualitative stability of nanofluids at various concentrations (2000, 1000, 500, 250, 100 and 50 ppm) along with the specified brines was discussed. Among synthesized brines, SW2S and SW2Ca caused more instability in solutions due to more concentration of $\mathrm{SO}_{4}{ }^{2-}$ and $\mathrm{Ca}^{2+}$. 
The results show that the nanofluids were unstable in all concentrations and quickly formed white sediment, except at concentrations of 100 and $50 \mathrm{ppm}$. Figure S1 demonstrates the sediment formation of these samples (nanofluid with SW2S). As shown in Figure S2, the nanofluid with a concentration of $100 \mathrm{ppm}$ with synthetic seawater formed little precipitate after $24 \mathrm{~h}$ while at $50 \mathrm{ppm}$ concentration, it remained stable over 3 days without formation of any sediment. In addition, the stability of nanofluid (at $50 \mathrm{ppm}$ ) was checked over a week and the images showed no change, which means that the nanofluid was stable at this concentration. As shown in Figure S3, immediately after the preparation of these solutions (different concentrations of nanofluids with $\mathrm{SW} 2 \mathrm{Ca}$ ), the nanoparticle aggregation occurs. Figures S1, S2 and S3 are presented in electronic supplementary information. With the addition of calcium ions, they are attracted to the negatively charged nanoparticles, reducing their negative surface charge. In other words, divalent cations like $\mathrm{Ca}^{2+}$ can be effective in neutralizing negatively charged nanoparticles. Hence, van der Waals gravity forces between particles become greater than electrostatic repulsive ones causing agglomeration and instability of the solutions. Figure 5 illustrates the schematic of this mechanism.

Several DLS measurements were performed to investigate the quantitative stability of nanoparticles in different brines. The average particle sizes of following solutions (100-SW0Ca, 100-SW2Ca, 100-SW0S, 100-SW2S, 50-SW0Ca, 50-SW2Ca, 50-SW0S, 50-SW2S, 100 and 50 show the concentration of nanofluid in $\mathrm{ppm}$ ) were measured at one, three and 7 days $(24,72,168 \mathrm{~h})$ without shaking them to investigate the particle size changes due to natural precipitation. Generally, in unstable solutions, the diameter of the nanoparticles decreased due to the deposition of larger particles from the first to the last day of measurement. Table 4 demonstrates the average diameter of the nanoparticles in the solutions listed. The average diameter of particles in solutions containing $100 \mathrm{ppm}$ of nanofluid was only measurable in the first 2 days because on the seventh day these solutions completely precipitated and the concentration of particles in suspension was reduced to a level that was not detectable. Thus, the mean diameter of particles decreased over time and only smaller particles stayed in the solution while larger ones precipitated at the bottom of the container. According to Table 4, solutions containing $50 \mathrm{ppm}$ of nanofluid remained quite stable. In other word, the average size obtained from DLS at day 1 and day 7 was almost similar. Figure 6 illustrates the particle size distribution for the 100-SW2S solution at

Table 4 The average diameters of nanoparticles at different times from their preparation by DLS measurements

\begin{tabular}{llcc}
\hline Solution & \multicolumn{3}{l}{ Diameter at different standing times, $\mathrm{nm}$} \\
\cline { 2 - 4 } & $24 \mathrm{~h}$ & $72 \mathrm{~h}$ & $168 \mathrm{~h}$ \\
\hline 100-SW0Ca & 85 & 60 & - \\
100-SW2Ca & 80 & 53 & - \\
100-SW0S & 87 & 60 & - \\
100-SW2S & 78 & 50 & - \\
50-SW0Ca & 91 & 90 & 90 \\
50-SW2Ca & 93 & 93 & 91 \\
50-SW0S & 91 & 90 & 90 \\
50-SW2S & 94 & 93 & 93 \\
\hline
\end{tabular}

Note: 100 and 50 show the concentration of nanofluid in ppm

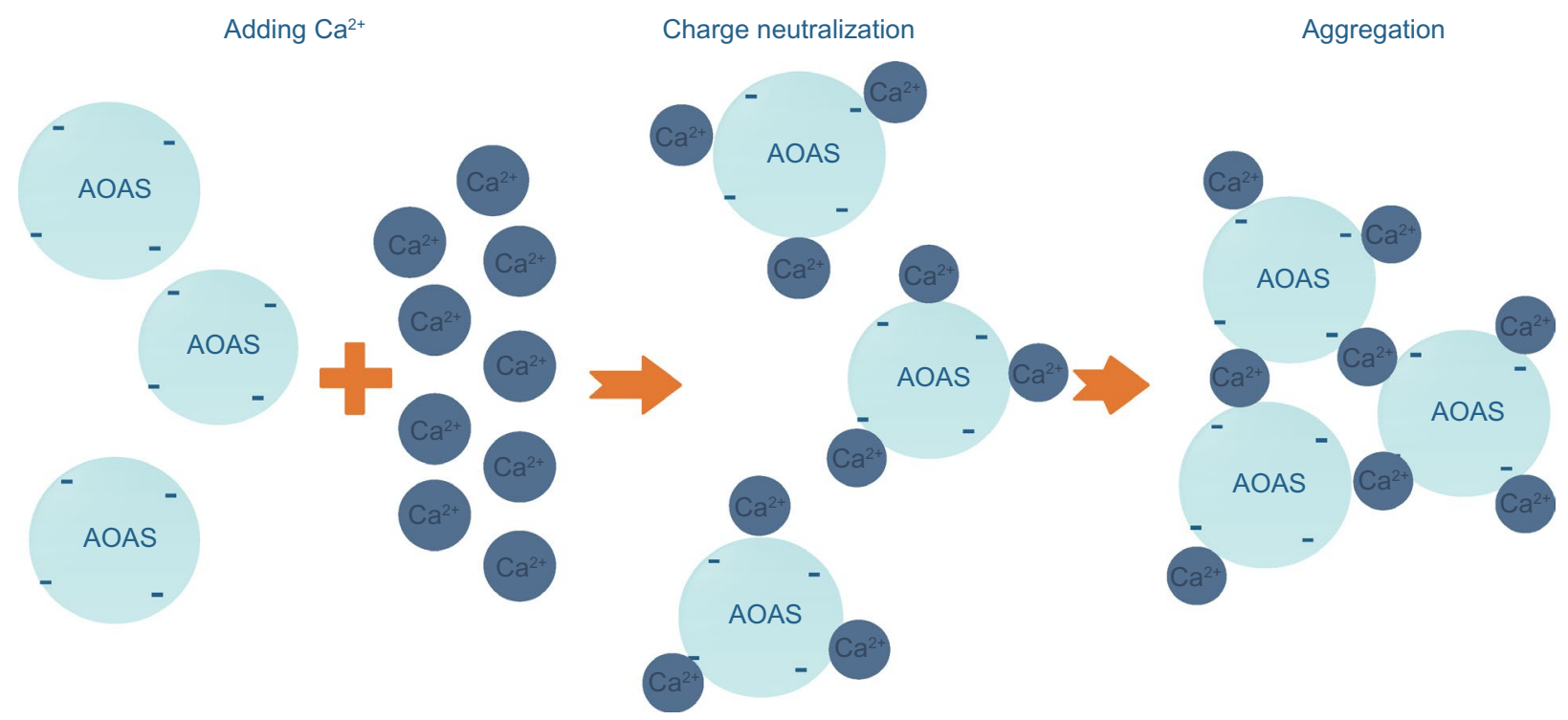

Fig. 5 The schematic of nanoparticle aggregation mechanism by adding $\mathrm{Ca}^{2+}$ 


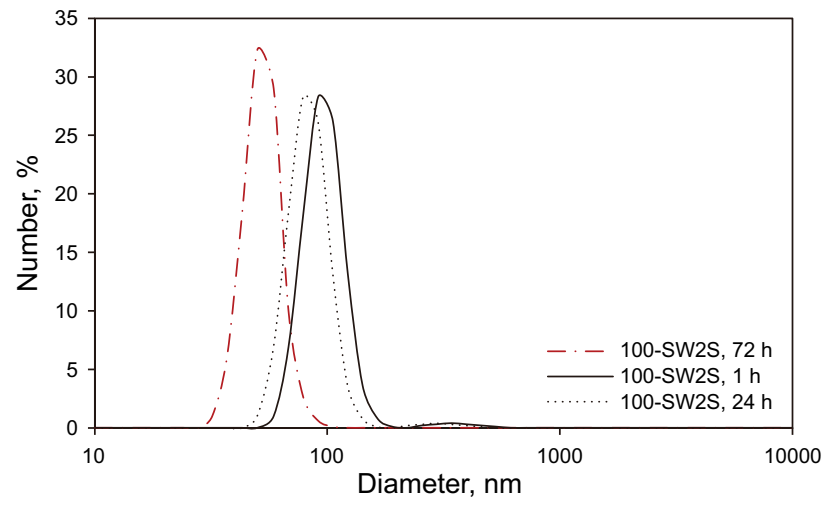

Fig. 6 Nanoparticle size distribution for 100 ppm nanofluid along with SW2S solution (100-SW2S) after standing for 1, 24, and $72 \mathrm{~h}$

$1 \mathrm{~h}$, day 1 (24 h), day 3 (72 h). In addition, the quantitative stability of the solutions shows that the light absorption amount of nanofluids is significantly reduced at $100 \mathrm{ppm}$ with specified synthetic seawater. As a result, these solutions are rapidly unstable, confirming the qualitative results. Figure 7 a demonstrates these observations. However, as shown in Fig. 7b, the change in the light absorption amount of nanofluids at a concentration of $50 \mathrm{ppm}$ is not very tangible and the solution is stable. Therefore, in order to ensure that the injected fluid is stable during the core flooding time period, $50 \mathrm{ppm}$ of the nanofluid was selected. The stability of a solution is justified by the use of DLVO theory. In fact, by increasing the electrolyte concentration, the repulsion forces between the particles are reduced and the van der Waals gravity forces increase. This leads to the absorption of nanoparticles into each other and eventually the formation of a sediment. Therefore, interactions of the particles and these forces increase in the presence of brines and high concentrations of nanofluid and the solution becomes more unstable.

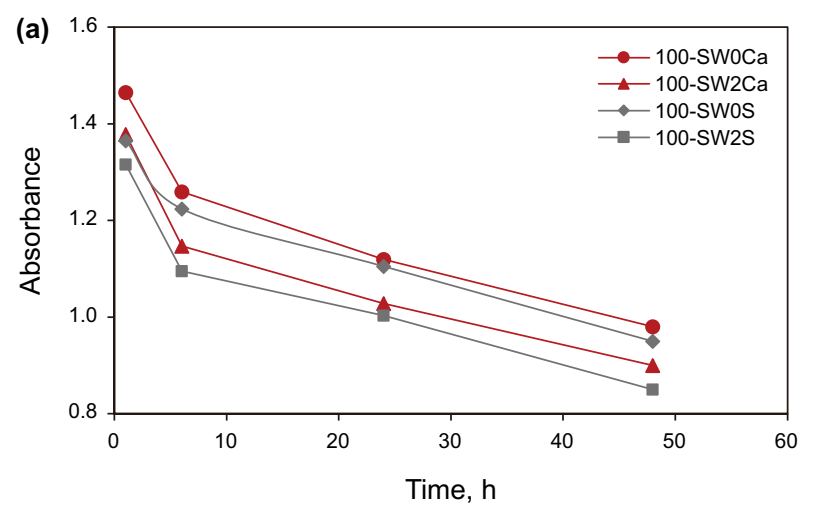

\subsection{Contact angle and IFT measurements}

This section discusses how the carbonate rock wettability changes in the presence of the specified synthetic seawater and these brines with $50 \mathrm{ppm}$ nanofluid. Figure 8 shows the results of these measurements in brines and brines with nanofluid solutions, respectively, after $72 \mathrm{~h}$. As observed in Fig. 8a, the addition of calcium ions to the brine solution (SW0Ca, SW2Ca) increases the ability to change the wettability. In other words, in the absence of calcium ion, sulfate ion as the ion pair of $\mathrm{Ca}^{2+}$ cannot change the wettability of the media alone, and thus, the improvement of oil recovery factor is not significant. As presented in Fig. 8b, the contact angle decreases dramatically by the addition of nanofluid to saltwater solutions, which is a sign of the high strength of the nanofluid to modify the wettability and change the surface toward water wetness. These observations can be related to the fact that the nanofluids with negative surface charge rapidly move toward the positive surface of carbonates and reduce their positive charge. Due to the reduction of repulsive electrostatic forces, the concentration of $\mathrm{Ca}^{2+}$ ions increases near the surface. Thus, these ions adhere to the negatively charged carboxyl groups of crude oil and separate them from the surface. In addition, Fig. 8 a shows the effect of sulfate ion on the wettability alteration of oil wet surfaces. As observed in Fig. 8, increasing the concentration of sulfate ions reduces the contact angle significantly. Figure $8 \mathrm{~b}$ demonstrates that the addition of nanofluid to synthetic seawater solutions (SW0S and SW2S) considerably reduces the contact angle and changes the oil wet surfaces to strongly water wet. The nanofluid with negative charge helps sulfate ion neutralize the positive charge of the surface. As a result, calcium ions approach the surface and separate oil droplets more easily. According to the obtained data, brine containing twice the concentration of sulfate ions along with nanofluid has the greatest impact on reducing the contact angle and water wetting of the surface up to $38^{\circ}$.

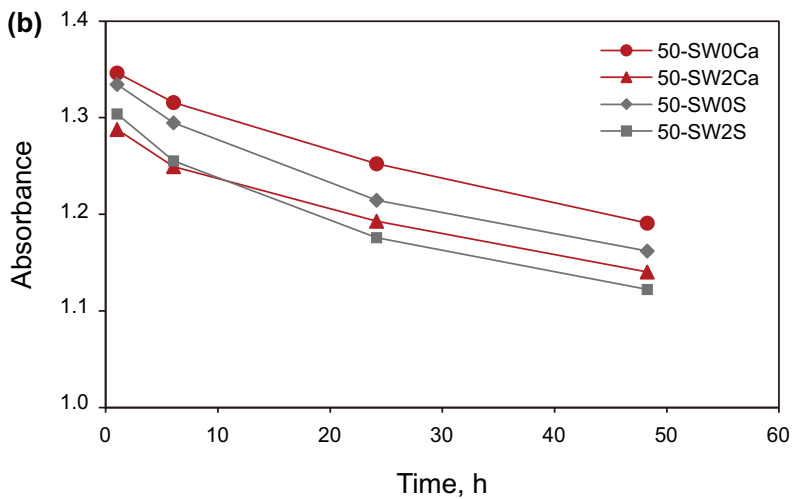

Fig. 7 UV-visible absorption of nanofluids at concentrations of a 100 and b 50 ppm in different brine samples 
(a)

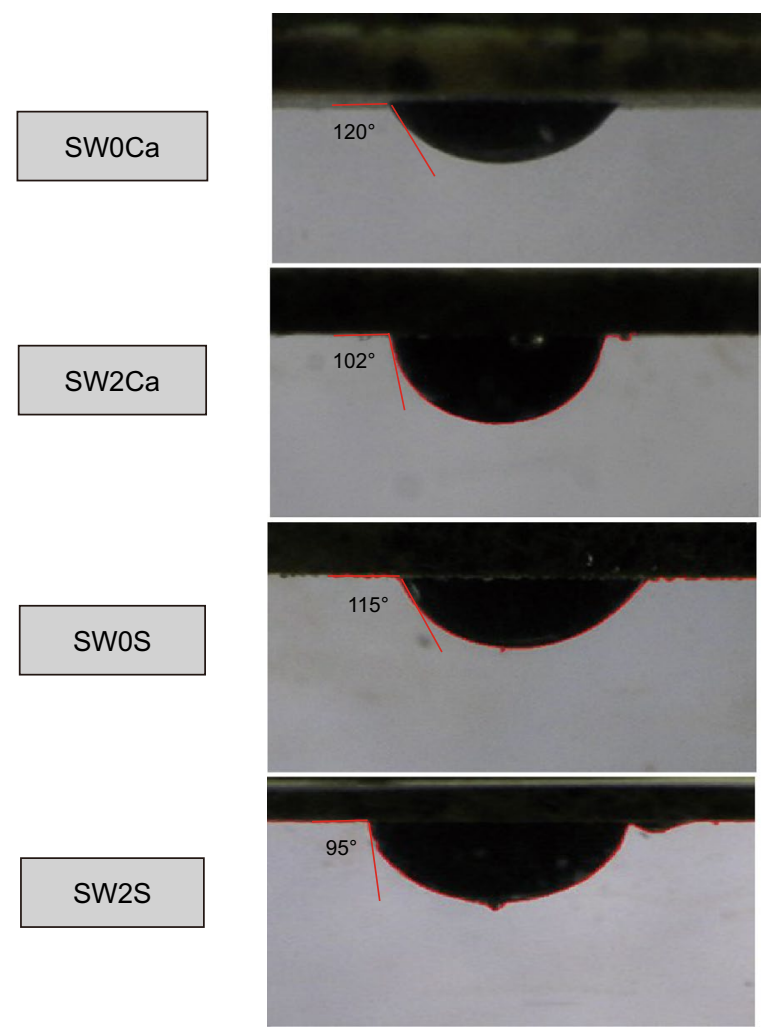

(b)

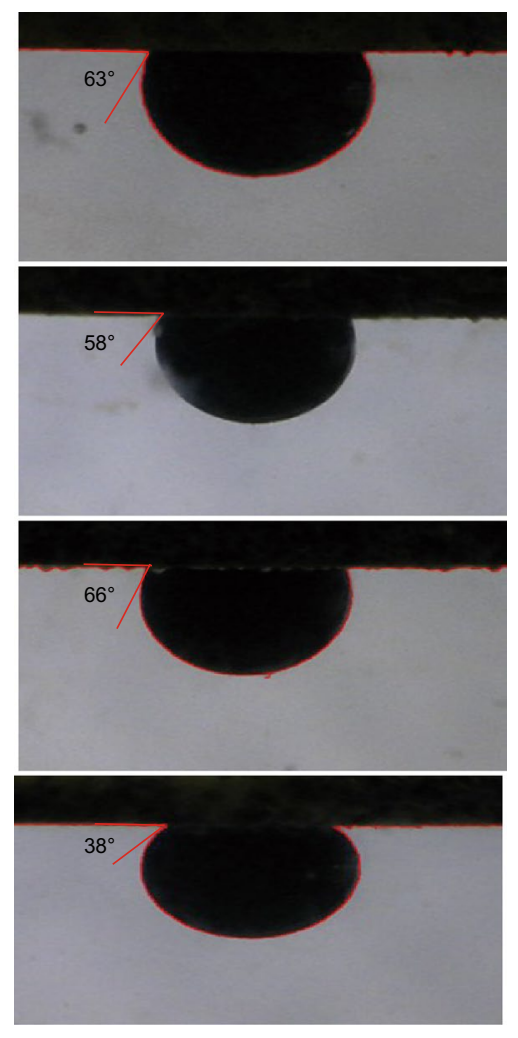

Fig. 8 Results of contact angle measurements on carbonate surfaces after $72 \mathrm{~h}$ of soaking in a brines (SW0Ca, SW2Ca, SW0S and SW2S) and b the same brines with $50 \mathrm{ppm}$ nanofluid

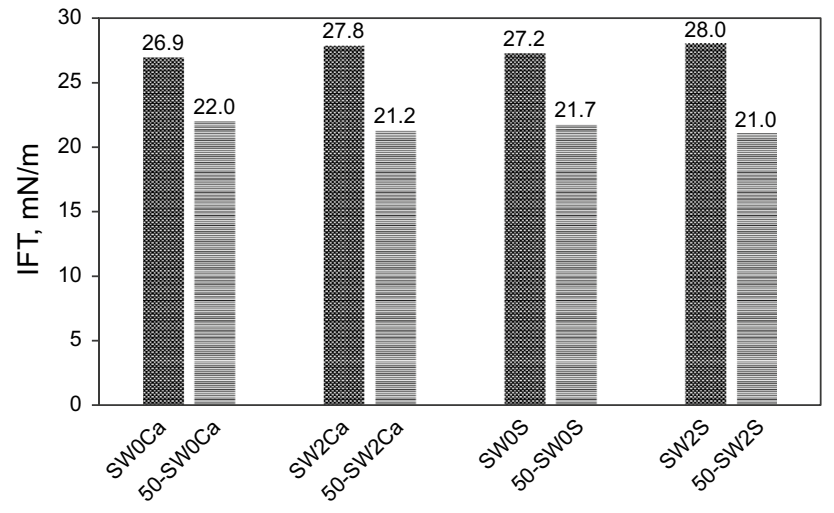

Fig. 9 Effect of smart water (SW0Ca, SW2Ca, SW0S and SW2S) and nanocomposite (AOAS) on IFT values

On the other hand, the influence of synthetic seawater (smart water) and nanocomposite on IFT values are illustrated in Fig. 9. This figure demonstrates that the interfacial tension is not sensitive to the ionic composition of smart waters. Furthermore, by adding $50 \mathrm{ppm}$ modified $\mathrm{Al}_{2} \mathrm{O}_{3} /$ $\mathrm{SiO}_{2}$ nanocomposite to smart water solutions, the IFT values are reduced. A comparison of the results of contact angle with IFT values indicates the higher potential of this nanocomposite in wettability alteration than IFT reduction. Thus, the main mechanism for improving oil recovery is wettability alteration.

\subsection{Core flooding and ionic analysis}

As noted above, the core flooding tests were carried out in three steps, respectively, by injection of seawater, smart water and smart water along with the nanofluid. Core samples 1 and 2 were used to evaluate the effect of various concentrations of calcium ion. As observed in Fig. 10a, first, 4 pore volumes of seawater were injected into core sample 1 and the oil recovery of the seawater flooding was 43.9\%. In the next steps (injection of smart water SW0Ca and smart water with $50 \mathrm{ppm}$ nanofluid), the corresponding values were $49.2 \%$ and $53 \%$, respectively. In addition, the oil recovery factors for core sample 2 (injection of SW2Ca) in each step were $44.0 \%, 53.0 \%$ and $58.5 \%$, respectively. Therefore, by comparing the oil recovery of second steps for core samples 1 and 2, it can be concluded that an increase in the concentration of calcium ions significantly improves the oil recovery. In fact, it will change the wettability of the rock surface to more water wet according to the previous section and improve the oil recovery. In other words, the number 

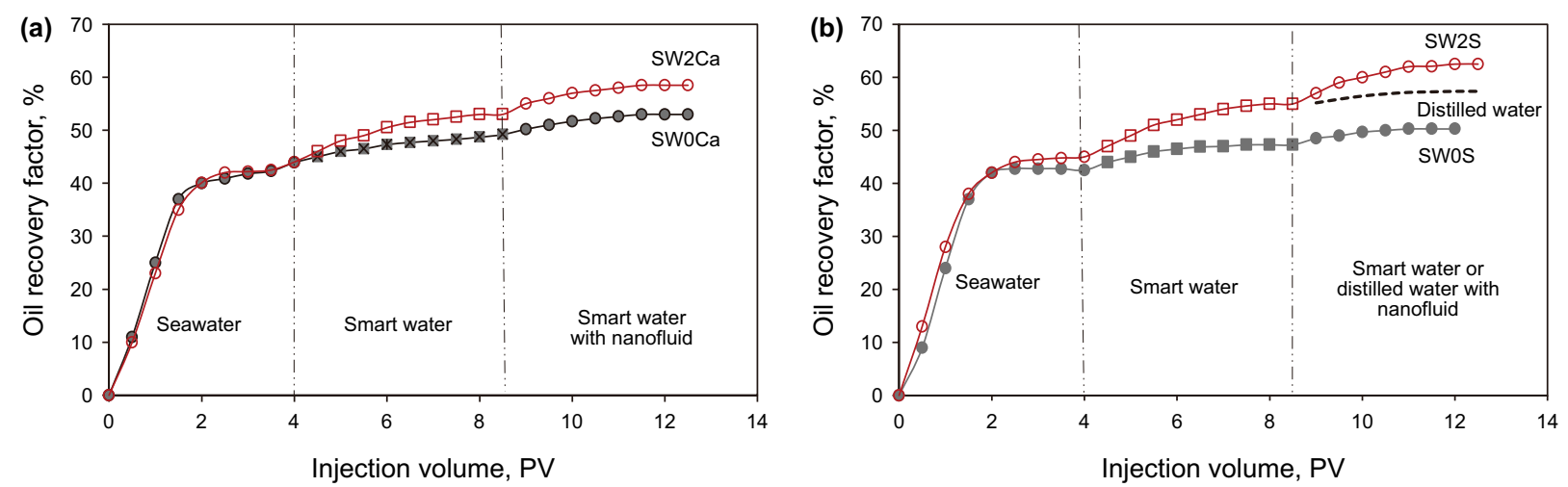

Fig. 10 Oil recovery factor versus injection volume at various concentrations of $\mathbf{a}$ calcium and $\mathbf{b}$ sulfate ions

of calcium ions stuck to the carboxyl groups increases and further separates the oil from the surface. Moreover, as observed in Fig. 10b, the oil recovery factors for core sample 3 (injection of SWOS) in each step were $42.5 \%, 47.3 \%$ and $50.3 \%$, respectively, and the corresponding values for core sample 4 (injection of SW2S) were $45.0 \%, 55.0 \%$ and $62.5 \%$, respectively. The results showed that adding nanofluid to the solutions increased the oil recovery factor by about 3\% to $7 \%$ in all cases. This increase in oil recovery for SW2S is more than those of other brines. On the other hand, a coreflood test was performed to investigate the ability of AOAS nanofluid without the presence of smart water in oil displacement. Thus, $50 \mathrm{ppm}$ of AOAS nanocomposite solution in distilled water was prepared and injected into the core. As shown in Fig. 10b, the oil recovery of nanofluid injection was about $57.4 \%$. However, higher oil recovery would be achieved by injecting smart water with nanofluids. Therefore, the injection of smart water with nanofluid has a great ability to displace oil in comparison with nanofluid only (AOAS in pure water).

These observations are consistent with the results obtained at contact angle section. As observed, the addition of nanofluid makes the rock surface strongly water wet. This will cause the oil drop to be removed from the surface and recover it more. In order to determine the mechanism governing the system, ion analysis was carried out by measuring the concentration of the ions in the effluent during core flooding tests. According to Fig. 11, the decrease in sulfate ion concentration in the outlet indicates that these ions were adsorbed to the positively charged carbonate surface. Due to the decreased net positive charge of the rock surface, calcium ions then tend to approach the surface and stick to the negatively charged carboxylic groups of oil to separate it from the surface. Finally, these processes change the rock wettability. Therefore, ion exchange is one of the main mechanisms for wettability alteration of cores. Moreover, the increase in calcium ion concentration in the outlet verifies the dissolution of carbonate rock into the liquid phase.

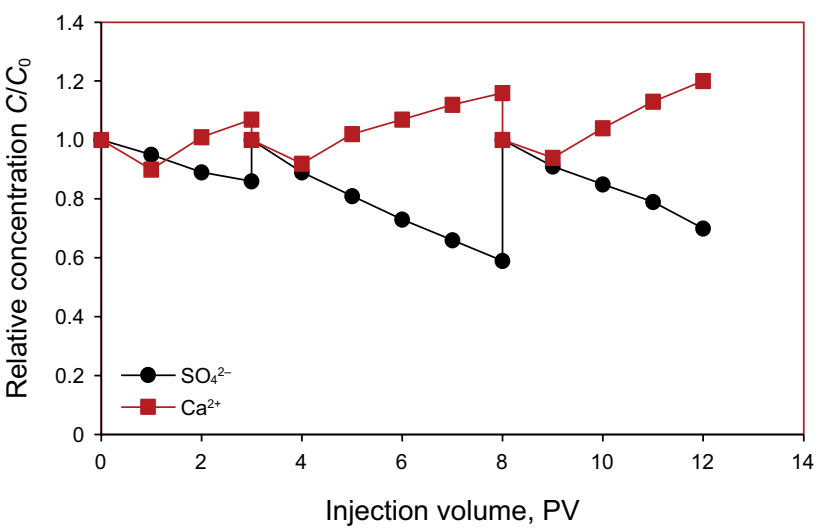

Fig. 11 Ion analysis of effluent versus injection volume in the core flooding test for core sample 4 (injection of SW2S), $C$ and $C_{0}$ are ion concentrations in the injection fluid and effluent, respectively

Figure 12 shows these phenomena. In other words, calcium carbonate is dissolved to balance the calcium concentration in the brines. When the rock is dissolved, more calcium ions are released and connected to the carboxyl groups and consequently produce more oil. These two mechanisms lead to the greater separation of oil from the carbonate surfaces and increase the oil efficiency in core flooding tests.

\section{Conclusions}

In summary, for the first time, synthetic nanocomposite AOAS with smart water has been used as a new method for wettability alteration of carbonate rock. Based on the experimental results, smart water solutions at $50 \mathrm{ppm}$ concentration of nanofluid showed acceptable stability during the flooding period. By increasing the concentration of active ions such as $\mathrm{Ca}^{2+}$ and $\mathrm{SO}_{4}{ }^{2-}$, the ion exchange mechanism was activated, and as a result, the contact angle decreased and the rock wettability shifted toward water wetness. In 


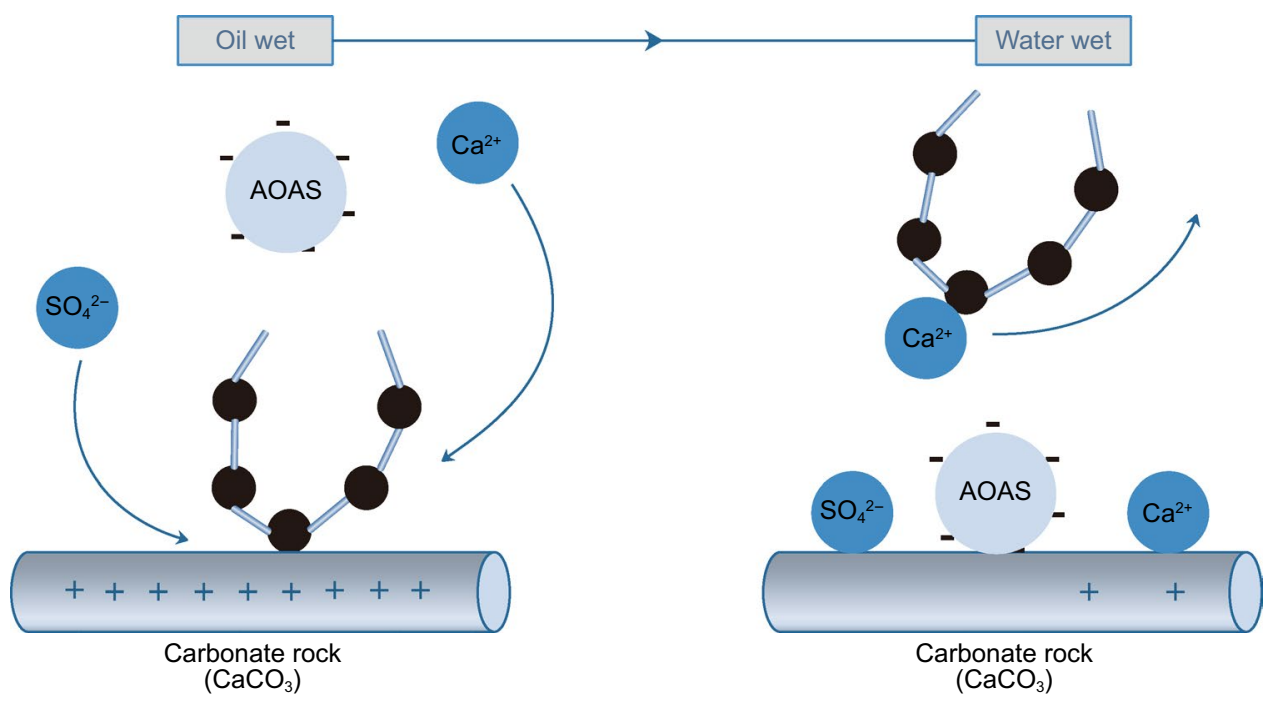

Fig. 12 The schematic of wettability alteration mechanism for smart water with nanofluid

addition, the contact angle dropped sharply by adding nanoparticles to brine solutions. This reduction was higher in the SW2S smart water solution and made the rock surface strongly water wet. On the other hand, the increase in the concentration of $\mathrm{Ca}^{2+}$ and $\mathrm{SO}_{4}{ }^{2-}$ ions significantly improved the oil recovery. In addition, investigating the effect of nanofluid present in SW0Ca, SW2Ca, SW0S and SW2S solutions on oil recovery factor during flooding period showed that they could increase this coefficient very well. This increase in oil recovery was $7.5 \%$ for SW2S. According to ion analysis, dissolution of carbonates and ion exchange mechanisms increased the tendency of oil to separate from the rock surface, changed the wettability and finally improved oil recovery factor.

Acknowledgments The authors would like to acknowledge the National Iranian Oil Company and Tarbiat Modares University for their support throughout this study.

Open Access This article is licensed under a Creative Commons Attribution 4.0 International License, which permits use, sharing, adaptation, distribution and reproduction in any medium or format, as long as you give appropriate credit to the original author(s) and the source, provide a link to the Creative Commons licence, and indicate if changes were made. The images or other third party material in this article are included in the article's Creative Commons licence, unless indicated otherwise in a credit line to the material. If material is not included in the article's Creative Commons licence and your intended use is not permitted by statutory regulation or exceeds the permitted use, you will need to obtain permission directly from the copyright holder. To view a copy of this licence, visit http://creativecommons.org/licenses/by/4.0/.

\section{References}

Al-Anssari S, Barifcani A, Wang S, Maxim L, Iglauer S. Wettability alteration of oil-wet carbonate by silica nanofluid. J Colloid Interface Sci. 2016;461:435-42. https://doi.org/10.1016/j. jcis.2015.09.051.

Awolayo A, Sarma H, AlSumaiti A. An experimental investigation into the impact of sulfate ions in smart water to improve oil recovery in carbonate reservoirs. Transp Porous Media. 2016;111(3):649-68. https://doi.org/10.1007/s11242-015-0616-4.

Behzadi A, Mohammadi A. Environmentally responsive surface-modified silica nanoparticles for enhanced oil recovery. J Nanopart Res. 2016;18(9):266. https://doi.org/10.1007/s11051-016-3580-1.

Binks BP, Whitby CP. Silica particle-stabilized emulsions of silicone oil and water: aspects of emulsification. Langmuir. 2004;20(4):1130-7. https://doi.org/10.1021/la0303557.

Damayanti N. Preparation of superhydrophobic PET fabric from $\mathrm{Al}_{2} \mathrm{O}_{3}-\mathrm{SiO}_{2}$ hybrid: geometrical approach to create high contact angle surface from low contact angle materials. J Sol-Gel Sci Technol. 2010;56(1):47-52. https://doi.org/10.1007/s1097 1-010-2271-0.

Elyaderani SMG, Jafari A. Microfluidics experimental study in porous media applied for nanosilica/alkaline flooding. J Pet Sci Eng. 2019;173:1289-303. https://doi.org/10.1016/j.petro 1.2018.08.039.

Elyaderani G, Seyed M, Jafari A, Razavinezhad J. Experimental investigation of mechanisms in functionalized multiwalled carbon nanotube flooding for enhancing the recovery from heavy-oil reservoirs. SPE J. 2019;24(6):2681-94. https://doi. org/10.2118/194499-PA.

Engeset B. The potential of hydrophilic silica nanoparticles for EOR purposes: a literateur review and an experimental study. MS thesis. 2012, Institutt for petroleumsteknologi og anvendt geofysikk. https://ntnuopen.ntnu.no/ntnu-xmlui/handle/11250/239771.

Fan H, Striolo A. Nanoparticle effects on the water-oil interfacial tension. Phys Rev E. 2012;86(5):051610. https://doi.org/10.1103/ physreve.86.051610.

Gao Y, Marín L, Mattson EC, Cure J, Nanayakkara CE, Veyan J-F, et al. Basic mechanisms of $\mathrm{Al}$ interaction with the $\mathrm{ZnO}$ surface. 
J Phys Chem C. 2017;121(23):12780-8. https://doi.org/10.1021/ acs.jpcc.7b02661.

Gharibshahi R, Jafari A, Haghtalab A, Karambeigi MS. Application of CFD to evaluate the pore morphology effect on nanofluid flooding for enhanced oil recovery. RSC Adv. 2015;5(37):28938-49. https ://doi.org/10.1039/C4RA15452E.

Hendraningrat L, Torsæter O. A study of water chemistry extends the benefits of using silica-based nanoparticles on enhanced oil recovery. Appl Nanosci. 2016;6(1):83-95. https://doi.org/10.1007/ s13204-015-0411-0.

Johnson LM, Gao L, Shields CW IV, Smith M, Efimenko K, Cushing $\mathrm{K}$, et al. Elastomeric microparticles for acoustic mediated bioseparations. J Nanobiotechnol. 2013;11(1):22. https://doi. org/10.1186/1477-3155-11-22.

Karimi A, Fakhroueian Z, Bahramian A, Pour Khiabani N, Darabad JB, Azin R, et al. Wettability alteration in carbonates using zirconium oxide nanofluids: EOR implications. Energy Fuels. 2012;26(2):1028-36. https://doi.org/10.1021/ef201475u.

Kiani S, Mansouri Zadeh M, Khodabakhshi S, Rashidi A, Moghadasi J. Newly prepared Nano gamma alumina and its application in enhanced oil recovery: an approach to low-salinity waterflooding. Energy Fuels. 2016;30(5):3791-7. https://doi.org/10.1021/ acs.energyfuels. 5 b03008.

Kokal S, Al-Kaabi A. Enhanced oil recovery: challenges \& opportunities. World Petroleum Council: Official Publication; 2010. p. 64.

Kong X, Ohadi M. Applications of micro and nano technologies in the oil and gas industry-overview of the recent progress. In: Abu Dhabi international petroleum exhibition and conference; 2010. Society of Petroleum Engineers. https://doi.org/10.2118/13824 1-MS.

Lan Q, Yang F, Zhang S, Liu S, Xu J, Sun D. Synergistic effect of silica nanoparticle and cetyltrimethyl ammonium bromide on the stabilization of O/W emulsions. Colloids Surf, A. 2007;302(13):126-35. https://doi.org/10.1016/j.colsurfa.2007.02.010.

Lei S, Xu L, Qu C, Jiao H. Influence of gemini surfactant with modified $\mathrm{TiO}_{2}$ nanoparticles on the interfacial tension of oil/water. J Dispers Sci Technol. 2016;37(10):1494-501. https://doi. org/10.1080/01932691.2015.1015076.

Li S, Kaasa AT, Hendraningrat L, Torsæter O. Effect of silica nanoparticles adsorption on the wettability index of Berea sandstone. Paper SCA2013-059 presented at the international symposium of the society of core analysts held in Napa Valley, California, USA. 2013.

Metin CO, Lake LW, Miranda CR, Nguyen QP. Stability of aqueous silica nanoparticle dispersions. J Nanopart Res. 2011;13(2):83950. https://doi.org/10.1007/s11051-010-0085-1.

Metin CO, Baran JR, Nguyen QP. Adsorption of surface functionalized silica nanoparticles onto mineral surfaces and decane/water interface. J Nanopart Res. 2012;14(11):1246. https://doi.org/10.1007/ s11051-012-1246-1.

Nazari Moghaddam R, Bahramian A, Fakhroueian Z, Karimi A, Arya S. Comparative study of using nanoparticles for enhanced oil recovery: wettability alteration of carbonate rocks. Energy Fuels. 2015;29(4):2111-9. https://doi.org/10.1021/ef5024719.

Nwidee L, Al-Anssari S, Barifcani A, Sarmadivaleh M, Iglauer S. Nanofluids for enhanced oil recovery processes: wettability alteration using zirconium oxide. In: Offshore Technology Conference Asia; 2016. Offshore Technology Conference. https://doi. org/10.4043/26573-MS

Pierre A, Lamarche J, Mercier R, Foissy A, Persello J. Calcium as potential determining ion in aqueous calcite suspensions. J Dispers Sci Andtechnol. 1990;11(6):611-35. https://doi. org/10.1080/01932699008943286.
Puntervold T, Strand S, Ellouz R, Austad T. Modified seawater as a smart EOR fluid in chalk. J Pet Sci Eng. 2015;133:440-3. https:// doi.org/10.1016/j.petrol.2015.06.034.

Qiu F. The potential applications in heavy oil EOR with the nanoparticle and surfactant stabilized solvent-based emulsion. In: Canadian unconventional resources and international petroleum conference; 2010. Society of Petroleum Engineers. https://doi. org/10.2118/134613-MS.

Rashid S, Mousapour MS, Ayatollahi S, Vossoughi M, Beigy AH. Wettability alteration in carbonates during "Smart Waterflood": underlying mechanisms and the effect of individual ions. Colloids Surf, A. 2015;487:142-53. https://doi.org/10.1016/j.colsu rfa.2015.09.067.

Roustaei A, Bagherzadeh $\mathrm{H}$. Experimental investigation of $\mathrm{SiO}_{2}$ nanoparticles on enhanced oil recovery of carbonate reservoirs. J Pet Explor Prod Technol. 2015;5(1):27-33. https://doi.org/10.1007/ s13202-014-0120-3.

Roustaei A, Moghadasi J, Bagherzadeh H, Shahrabadi A. An experimental investigation of polysilicon nanoparticles' recovery efficiencies through changes in interfacial tension and wettability alteration. In: SPE international oilfield nanotechnology conference and exhibition; 2012. Society of Petroleum Engineers. https ://doi.org/10.2118/156976-MS.

Stosur GJ, Hite JR, Carnahan NF, Miller K. The alphabet soup of IOR, EOR and AOR: effective communication requires a definition of terms. In: SPE International Improved Oil Recovery Conference in Asia Pacific; 2003. Society of Petroleum Engineers. https://doi. org/10.2118/84908-MS.

Sulaiman WRW, Adala A, Junin R, Ismail I, Ismail AR, Hamid MA, et al. Effects of salinity on nanosilica applications in altering limestone rock wettability for enhanced oil recovery. In: Advanced Materials Research. 2015. Trans Tech Publications https://doi. org/10.4028/www.scientific.net/AMR.1125.200.

Sun Y, Zhang Z, Wong C. Study on mono-dispersed nano-size silica by surface modification for underfill applications. J Colloid Interface Sci. 2005;292(2):436-44. https://doi.org/10.1016/j. jcis.2005.05.067.

Tokoro C, Suzuki S, Haraguchi D, Izawa S. Silicate removal in aluminum hydroxide co-precipitation process. Materials. 2014;7(2):1084-96. https://doi.org/10.3390/ma7021084.

Yan H, Yuanhao W, Hongxing Y. TEOS/silane-coupling agent composed double layers structure: a novel super-hydrophilic surface. Energy Procedia. 2015;75:349-54. https://doi.org/10.1016/j.egypr o.2015.07.384.

Yousef AA, Al-Saleh SH, Al-Kaabi A, Al-Jawfi MS. Laboratory investigation of the impact of injection-water salinity and ionic content on oil recovery from carbonate reservoirs. SPE Reserv Eval Eng. 2011;14(05):578-93. https://doi.org/10.2118/137634-PA.

Yousefvand HA, Jafari A. Stability and flooding analysis of nanosil$\mathrm{ica} / \mathrm{NaCl} / \mathrm{HPAM} / \mathrm{SDS}$ solution for enhanced heavy oil recovery. J Pet Sci Eng. 2018;162:283-91. https://doi.org/10.1016/j.petro 1.2017.09.078.

Zhang P, Austad T. Wettability and oil recovery from carbonates: effects of temperature and potential determining ions. Colloids Surf, A. 2006;279(1-3):179-87. https://doi.org/10.1016/j.colsu rfa.2006.01.009.

Zhang P, Tweheyo MT, Austad T. Wettability alteration and improved oil recovery in chalk: the effect of calcium in the presence of sulfate. Energy Fuels. 2006;20(5):2056-62. https://doi.org/10.1021/ ef0600816. 